\title{
O modelo de perspectivas de sistemas de Mihaly Csikszentmihalyi como ferramenta no processo de desenvolvimento de produto
}

\author{
Mihaly Csikszentmihalyi's system perspective model as a tool in the product \\ development process
}

ALENCAR, Adailton Laporte de; Dr; UFPE - Universidade Federal de Pernambuco

adailtonlaporte@yahoo.com.br

CAVALCANTI, Virgínia Pereira; Drạ; UFPE - Universidade Federal de Pernambuco

cavalcati.virginia@gmail.com

\section{Resumo}

Este artigo tem o objetivo de descrever o Modelo de Perspectivas de Sistemas de Mihaly Csikszentmihalyi e sua contribuição para o processo de criação e como elemento essencial para o desenvolvimento de produtos de design. Nas metodologias usualmente apresentadas como recurso facilitador no processo de desenvolvimento de produtos, em sua maioria, não é evidenciado ou destacado o fator criatividade, restringindo-se apenas a técnicas e estímulos como condição de geração de ideias. A relação entre o Modelo de Perspectivas de Sistemas e o processo criativo em design ampliaria as possibilidades de compreensão dos fatores expoentes do processo criativo do indivíduo criador (indivíduo), dos critérios relevantes e imprescindíveis valorados pelos integrantes da audiência (campo), ou seja, os juízes que legitimam estas ideias e então da incorporação do produto legitimado na cultura (domínio).

Palavras Chave: design de produto; criatividade; Mihaly Csikszentmihalyi.

\begin{abstract}
This article aims to describe the Mihaly Csikszentmihalyi Systems Perspective Model and its contribution to the creation process and as an essential element for the development of design products. In the methodologies usually presented as a facilitating resource in the product development process, the creativity factor is not evidenced or highlighted, being restricted only to techniques and stimuli as a condition for generating ideas. The relationship between the Systems Perspective Model and the creative process in design would broaden the possibilities of understanding the exponent factors of the creative process of the creative individual (individual), of the relevant and essential criteria valued by the members of the audience (field), that is, the judges who legitimize these ideas and then the incorporation of the legitimized product into the culture (domain).
\end{abstract}

Keywords: product design, creativity, Mihaly Csikszentmihalyi. 


\section{Introdução}

A criatividade sempre foi motivo de grandes discussões não apenas entre os estudiosos da área da psicologia. Complexa em mensurá-la, multifacetada em conceitos, e até hoje, difícil encontrá-la.

Imerso no rico universo do design se encontra o maior responsável pela criação e concepção de quase tudo o que é material e imaterial. O designer tem a incumbência de dar forma aos produtos para que estes sejam consumidos, usados, adorados por um público cada vez mais exigente. Além da estética, funcionalidade, inovação, ergonomia, viabilidade construtiva, entre outros requisitos relevantes, o valor emocional incorporado à peça tem sido ultimamente um grande aliado no projeto. O profissional responsável pela criação certamente deverá se carregar de motivações intrínsecas e extrínsecas para configurar um produto que atenda aos potenciais consumidores.

Este artigo descreve o Modelo de Perspectivas de Sistemas de Mihaly Csikszentmihalyi, psicólogo de origem húngara conhecido pelos seus trabalhos sobre o estudo da felicidade e da criatividade, e sua contribuição para o campo do design. Neste modelo preconizado por Mihaly, infere-se que a criatividade é movida por uma tríade composta pelo indivíduo (criador), pelo campo (quem legitima) e pelo domínio (cultura).

O Modelo de Perspectivas de Sistemas de Mihaly Csikszentmihalyi foi objeto de pesquisa da Tese de Doutorado apresentada pelo autor deste artigo, desenvolvida no Programa de pósgraduação da Universidade Federal de Pernambuco.

A preocupação desta pesquisa foi a de alargar o conhecimento de estudantes e profissionais de design sobre os modelos e ferramentas comumente tomados como referência para criação e que apresentam uma estrutura restrita de abordagem e aprofundamento.

A pesquisa traz definições mais abrangentes referentes a cada subsistema da tríade, para que o modelo possa ser utilizado e empregado por demais profissionais da área de design em seu processo criativo, além de preencher possíveis lacunas ainda abertas nos processos e métodos tradicionalmente utilizados.

A crença é que o profissional de design terá seguramente maiores e melhores condições em direcionar seus elementos de erudição durante o processo criativo. Do mesmo modo, é preciso relevar que o uso de habilidades pessoais e a aquisição de conhecimento de domínio precisarão ser complementados com uma compreensão complexa do modo como o campo funciona e toma decisões.

O modelo será detalhado a seguir.

\section{O modelo de perspectivas de sistemas de Mihaly Csikszentmihalyi}

Podemos dividir os estudos em criatividade de Mihaly Csikszentmihalyi em dois momentos importantes. De acordo com (Morais,2001) nos seus primeiros trabalhos, Mihaly buscava encontrar características que tornavam o indivíduo criativo, e por isso, pesquisava pontos que ele julgava relevantes na pessoa como a personalidade, valores, capacidade de resolução de problemas por exemplo.

Em um segundo momento, asseverou que as realizações criativas não poderiam ser 
esclarecidas e elucidadas apenas por variantes individuais, ou seja, o indivíduo deveria ser estudado e compreendido de forma holística pensando-se (Morais,2001) da seguinte maneira "do contexto do indivíduo tinha que se passar ao indivíduo em contexto". Mihaly então preconiza um modelo ativo que busca entender melhor o ato criativo e sugere a interação de uma tríade que se inter-relaciona constantemente municiada pelo indivíduo (ser criativo), o domínio (um composto estável inerente à área ou ao conhecimento) campo (audiência que legitima a ideia e a insere no domínio)

Cada um desses três elementos tem a sua devida importância dentro do sistema e esta interação é suficiente para explicar o ser criativo.

Csikszentmihalyi $(2014$, p.51) destaca que é importante perceber que cada um dos três sistemas principais: indivíduo, campo, e domínio afetam uns aos outros, por sua vez, pode-se dizer que os três sistemas representam três "momentos" do mesmo processo criativo.

Em artigo recente intitulado "O modelo de sistemas de criatividade e suas aplicações ${ }^{1 "}$, Csikszentmihalyi apresenta três exemplos de emprego do seu modelo por outros profissionais e áreas não correlatas o que demonstra a eficácia do modelo. Uma aplicação ${ }^{2}$ foi feita pelo psicólogo neozelandês Philip McIntyre com a música Yesterday dos Beatles. Em um outro exemplo, um casal de chefs criou três volumes de livros definidos pela tríade que compõe a criatividade sob a perspectiva de Mihaly: A história da culinária (domínio), Grandes chefs (indivíduo) e Restaurantes e críticos de culinária (campo). O último exemplo de emprego do modelo está direcionado a área da astrofísica.

Com base no modelo de perspectivas, Csikszentmihalyi defende que os estudos em criatividade devem ser focados nos sistemas sociais e não apenas no indivíduo. Gardner (1994, p.151) já defendia a ideia de importância dos sistemas sociais e justifica que os julgamentos de criatividade são iminentes à comunidade dependendo fortemente de indivíduos especializados em determinados campos.

Mclntyre (2007) discorre em seu artigo que a busca crescente de modelos que confluem na pesquisa da criatividade de forma geral, evidencia a necessidade de olhar além do indivíduo no lançamento da inventividade, no que implica, uma mudança nas abordagens para as técnicas que se podem utilizar de forma a aprimorar as práticas da criatividade. Com base nos preceitos apresentados no Modelo de Perspectivas de Sistemas de Mihaly Csikszentmihalyi, McIntyre ratifica a tríade essencial do modelo esclarecendo que os usos das habilidades pessoais junto a aquisição de conhecimento de domínio carecem de uma compreensão multifacetada e complexa do modo como os campos funcionam e tomam decisões.

Quando Csikszentmihalyi afirma que três elementos ou forças são essenciais em qualquer consideração da criatividade: Talento individual ou Indivíduo; O Domínio; e O Campo que julgam a importância ou não dos indivíduos ou produtos; Mihaly assume a posição de que a criatividade não está intimamente ligada a nenhum elemento ou força única, ou nem a pares de forças; mas sim a um processo em que existe a interação desses três elementos. Csikszentmihalyi (1999) estabelece que a criatividade só pode ser determinada estudando a interação entre criadores,

\footnotetext{
${ }^{1}$ SIMONTON, Dean Keith. The Wiley Handbook of Genius. John Wiley \& Sons, 2014, pp.533-545.

${ }^{2}$ MCINTYRE, Phillip. Paul McCartney and the Creation of 'Yesterday': The Systems Model in Operation. Cambridge University Press, Vol. 25, No. 2, UK, (May, 2006), pp. 201-219.
} 
seus campos e domínios correlatos.

Csikszentmihalyi $(2014$, p.51) atenta que o ponto de partida do processo criativo é puramente arbitrário. Normalmente pode se pensar de imediato que a ideia floresça sobretudo por parte do indivíduo, no entanto, Mihaly elucida que a informação que vai junto com a ideia já existia bem antes dela chegar ao indivíduo, ou seja, já havia sido incorporado no sistema símbolo da cultura, das práticas comuns, da língua, do domínio. A título de exemplo, uma pessoa, por mais capaz ou qualificado que seja, se não tiver acesso à informação, não será capaz de fazer uma contribuição criativa. Um indivíduo não é capaz de escrever uma sinfonia criativa sem ter um conhecimento aprofundado do domínio, ou seja, o universo da música.

Portanto, ao demonstrar no seu modelo que o processo criativo pode partir de qualquer um dos subsistemas da tríade, Mihaly definitivamente sugere abandonarmos um modelo ptolemaico da criatividade na qual o indivíduo está no centro de tudo, para um modelo copernicano na qual a pessoa faz parte de um sistema de influências e informações mútuas ${ }^{3}$.

Mclntyre (2007) reforça a premissa fazendo uma alusão que assim como o ar, o pavio e faísca são elementos essenciais para que se obtenha fogo, e a falta de algum desses impossibilita a sua produção; os três elementos estabelecidos por Mihaly: Indivíduo, Domínio e Campo, são considerados elementos primordiais para a criação de uma ideia ou produto criativo, reforçando dessa maneira que o ato de fomentar a criatividade não está apenas no sujeito, mas nos demais componentes da tríade, podendo ser gerado por qualquer um deles. A seguir, encontra-se um gráfico referente ao modelo preconizado por Mihaly Csikszentmihalyi.

Figura 1 - Modelo de Perspectivas de Sistemas de Mihaly Csikszentmihalyi

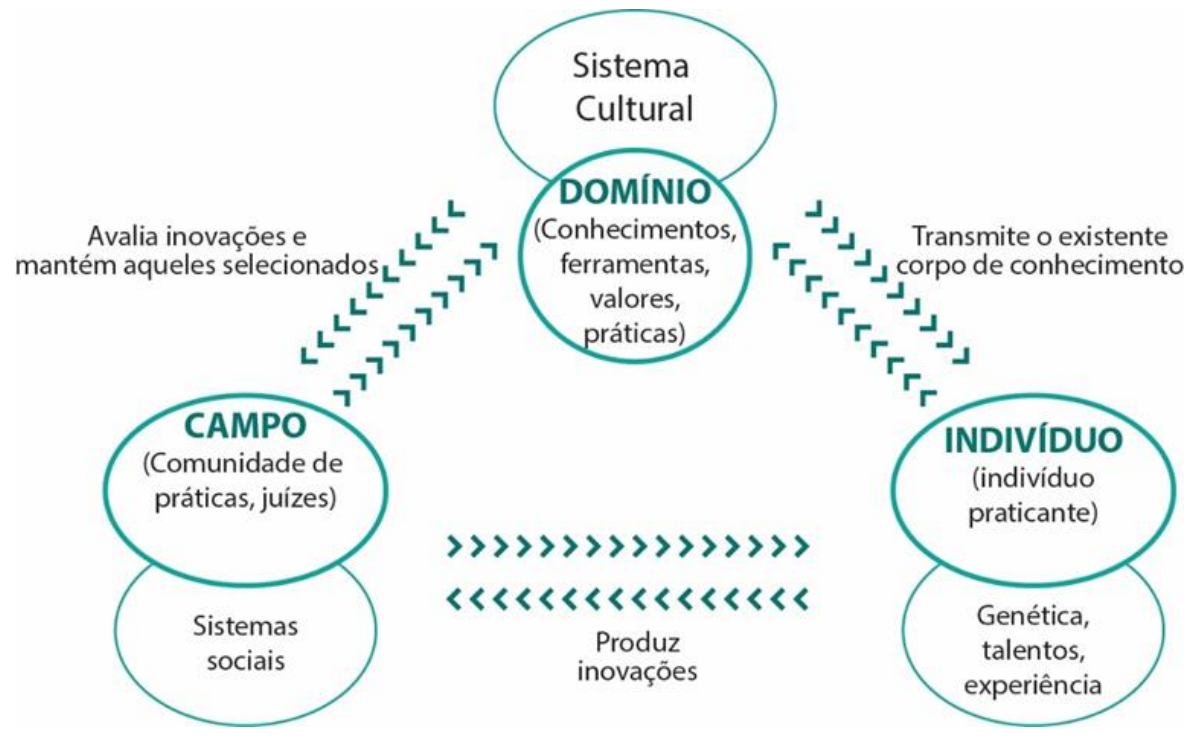

Fonte: Adaptado de Csikszentmihalyi (2014).

Com base no gráfico, será explicado cada elemento da tríade para melhor compreensão.

\footnotetext{
${ }^{3}$ Esse modelo proposto por Mihaly assevera que o processo criativo não reside apenas no indivíduo, mas que pode acontecer em qualquer um dos elementos da tríade.
} 


\subsection{Indivíduo}

O indivíduo produz variações e insere mudanças no domínio ou área de conhecimento.

O indivíduo é responsável pela variação do conteúdo do domínio e esta variação será então avaliada pelo campo, representado por especialistas e críticos que inserem essas instâncias de legitimação. Csikszentmihalyi (1999) acredita que a criatividade significa a capacidade de adicionar algo para a cultura. A criação do indivíduo deve ser corroborada por um grupo de especialistas que deverá ou não incorporar essa nova ideia no domínio.

Solomon (2009, p.227), no entanto, alerta quanto aos excessos por parte de professores rígidos, e o conservadorismo das organizações que levam a uma coibição da criatividade.

Um fator de grande valia consiste no indivíduo estar inserido num ambiente em que haja estímulos em produção criativa, que este possa ser valorizado no seu processo de aprendizagem e que sejam oferecidas oportunidades de acesso ao conhecimento com especialistas, livros, revistas, etc.

Existe, é claro, uma reunião de elementos formadores que favorece o indivíduo no que se diz respeito a produção de mudanças no domínio.

Esses elementos consistem no histórico pessoal do indivíduo, englobando o pool genético ${ }^{4}$ de onde provêm, experiências pessoais, abarcando também influência familiar, classe social e oportunidades educacionais, o tutor como figura de referência e elemento norteador no seu processo de construção do conhecimento. Esses elementos auxiliam no ingresso que o indivíduo pode ter ao domínio como também, é claro, ao campo. Nesse caso, o indivíduo deve passar por um processo de imersão no domínio em que assimilará novos códigos e convenções, assim como suas regras. É importante também que o indivíduo conheça o campo de modo que possa se socializar e entender, além de reconhecer suas normas e valores; e consequentemente a tomada de decisões quanto a seleção e escolha das novas ideias.

\subsection{Domínio}

Csikszentmihalyi aborda o domínio como um conjunto de regras e procedimentos simbólicos estabelecidos culturalmente que regulam a consciência humana (pensamentos, emoções, conhecimento acumulado, transmitido e compartilhado em uma sociedade ou por várias sociedades, crenças e atos intencionais tais como as várias tecnologias desenvolvidas ou adotadas no âmbito da cultura). Essas normas não são programadas para os conhecimentos genéticos herdados, mas sim uma absorção da interatividade com os demais membros da sociedade.

Tais normas transmitidas podem ser subdivididas em vários domínios por exemplo, o domínio da gastronomia contém instruções sobre como preparar alimentos. Milhares de receitas existem em muitas culturas e são transmitidas sob forma de instruções orais ou escritas de geração para geração. Centenas de domínios existem em cada cultura e a questão importante a ser considerada é que para um produto possa ser considerado criativo, este, precisa estar em um domínio já existente ou que estabeleça um novo domínio de normas.

Sobre os aspectos da cultura, Lubart $(2007$, p.83) refere como sendo "à divisão de um

\footnotetext{
${ }^{4}$ Um Pool Gênico é a população de cópias gênicas que são coletivamente mantidas pelos indivíduos de um deme. Demes são caracterizados por frequências genotípicas. Fonte: http://www.ufscar.br/ evolucao/grad/HW.pdf
} 
conjunto de pensamentos, de condutas, de tradições, de valores e de símbolos que estruturam o modo como um grupo de indivíduos vai interagir com seu ambiente psíquico e social". Lubart afirma que a cultura de uma comunidade é absorvida e passada a cada geração e que sua natureza evolui facilmente por meio de revoluções e inovações, mas também pela abertura à outras culturas.

Ostrower (1987, p.11) complementa as ideias de Lubart quando comenta que o comportamento de cada ser humano é moldado por princípios culturais, históricos, do grupo em que ele está inserido e, portanto, vive.

Sobre a questão dos avanços em um domínio, Csikszentmihalyi enfatiza que para que um matemático ou qualquer outro profissional se torne criativo por exemplo, ele deverá ter a capacidade de provar teoremas matemáticos que não foram capazes de serem resolvidos ou de se encontrar novos teoremas que ninguém havia pensado antes ou até mesmo de encontrar um novo sistema, um novo tipo de relação que ainda não fora posto em prática. Isso dará possibilidades de contestação pelos demais teóricos e estudiosos da área, ou seja, avanços em um domínio podem estimular avanços criativos em demais áreas assim como novas tecnologias podem ajudar a abrir novos domínios. Assim, como exemplifica Mihaly, Beethoven não poderia ter escrito seu opus 61 se os Luthieres de Cremona não tivessem se aperfeiçoado na arte de fazer violinos.

Portanto, por mais talentosa que seja a pessoa, seria muito pouco provável que ela possa contribuir de forma significativa caso ela não tenha acesso a um determinado domínio. Uma vez adquirida as informações a partir do domínio, esta pessoa será capaz de intervir por meio de motivações e estímulos. Por outro lado, grande parte das pessoas adquire conhecimento de um domínio para satisfação profissional sem intenção de aprimoramento ou inovação. Estes indivíduos podem ser grandes profissionais, mas sem poder de mudança de domínio.

\subsection{Campo}

O campo é a parte da sociedade que atua como gatekeeper ${ }^{5}$ ao domínio. Sua função seria de decidir se a nova ideia ou produto criativo é passível ou não de ser incluído no campo do domínio. Mihaly (2014, p.51) explica que a maneira mais fácil de descrever um campo, é dizer que este, inclui todas as pessoas que podem afetar a estrutura de um domínio.

Desse modo, no campo da arte se incluem, por exemplo, professores e historiadores de arte, que possuem informações pertinentes do domínio e as repassam para as próximas gerações. Os críticos de arte por exemplo, dão suporte aos artistas individuais; colecionadores, tem papel fundamental na manutenção das obras dos artistas e trabalhadores; os donos de galerias e curadores de museus, pela preservação e responsáveis pelo estado da arte na área. Por fim, o que Mihaly define como Peer Group ou grupo de pares de artistas cujo convívio define estilos e revoluções de gosto.

No entanto, é preciso esclarecer também que o campo também pode se equivocar: Sendo

\footnotetext{
${ }^{5}$ Essa teoria surgiu nos anos 50, nos Estados Unidos, como forma de deferência ao jornalismo e ao seu poder. Acredita que o processo de produção da informação é um processo de escolhas, no qual o fluxo de notícias tem que passar por diversos "gates" (portões) até a sua publicação. Entende que há intencionalidade no jornalismo e que o processo é arbitrário e subjetivo. Fonte: http://teoriadojornalismouniube.blogspot.com.br/2010/11/teoria-dogatekeeper.html
} 
muito rigoroso e criterioso, e pode assim descartar uma novidade que consequentemente poderia ser benéfica ao domínio, ou por precipitação prejudicando ou suprimindo o domínio.

Uma nova receita criada por um chef reconhecido será comentada por algum crítico gastronômico e com isso essa receita poderá figurar em edições futuras de respeitados livros da área da culinária. No entanto, caso os críticos sejam demasiadamente rígidos e pragmáticos a cozinha permanecerá tradicional e as novas receitas seriam ignoradas, por outro lado, se forem abertas a novas possibilidades e sabores, certamente serão incluídos no domínio.

Partindo desse antagonismo, ambas as estratégias podem ser perigosas: é possível destruir um domínio privando-o de novidades ou admitir demasiada novidade ainda não assimilada pelo domínio. Diante desse argumento, é possível dizer que a tarefa fundamental do campo seria selecionar variações promissoras e incorporá-las ao domínio.

Gardner (1986, p.111) define o campo como sendo uma organização social dentro do qual os indivíduos e os domínios coexistem, ou seja, quando os indivíduos se envolvem em uma ação ou domínio dentro de uma sociedade, eles estão necessariamente exercendo dentro do campo.

Mclntyre (2007) define o campo como um espaço estruturado que é organizado em torno de tipos específicos de conjuntos de conhecimentos de domínio. Mclntyre também delimita o conceito de campo como sendo uma arena de contestação onde ocorrem as posições competitivas dos atores em sua luta pela acumulação e monopolização de diferentes tipos de capital cultural e simbólico.

Mclntyre (2007, p.6) diz ainda que os campos podem atingir a criatividade de três formas:

Os campos podem afetar a criatividade de três maneiras diferentes; por ser reativo ou proativo, escolhendo um filtro amplo ou estreito para selecionar a novidade e estando "bem conectado ao restante do sistema social e, assim, capaz de canalizar o apoio" para esse domínio particular. Um campo reativo não solicita novidade enquanto que um proativo faz exigindo ativamente a novidade dos indivíduos criativos envolvidos. Além disso, alguns campos são conservadores e permitem que apenas alguns novos itens entrem no domínio a qualquer momento. Eles rejeitam a maior novidade e selecionam apenas o que consideram melhor. Outros são mais liberais ao permitir novas ideias em seus domínios, e como resultado, essas mudanças mais rapidamente. "Nos extremos, ambas as estratégias podem ser perigosas: é possível destruir um domínio ou privá-lo de novidade ou admitir demasiada novidade não-assimilada.

Percebe-se, nesse sentido, que o campo exerce influência sobre a criatividade do indivíduo. Isso indica que a criatividade não pode ser compreendida nem como algo meramente individual ou social, mas sim como uma interação dos diversos campos. Há, de fato, uma interdependência no processo criativo.

\section{A criatividade como elemento essencial no processo de desenvolvimento do produto}

O fenômeno da criatividade é de fato legitimado por sua amplitude em diversos cenários, vez que é um meio para o ser humano poder reconhecer suas potencialidades. Isso considerando que o homem vive em constante evolução e busca por incessantes inovações.

Guilford (1950, p.444), ao definir a criatividade e, por conseguinte suas características, afirma que o indivíduo que tem as habilidades necessárias, produzirá realmente resultados de natureza criativa a depender de sua motivação e temperamento. Guilford vai além e apresenta as 
características comportamentais do indivíduo criativo em aptidões, interesses, atitudes e qualidades temperamentais. Quanto às aptidões, esta característica define se esta pessoa está pronta para aprender a fazer certos tipos de tarefas.

O estímulo, quanto a esse atributo, Guilford não confirma, mas sugere ser provocada por determinação hereditária ou por determinação ambiental, ou quase sempre pela interação desses dois elementos. No que se refere ao interesse, comumente significa a inclinação da pessoa ou ânsia de se envolver em algum tipo de atividade. Quanto a atitude, consiste na tendência a conceder ou não algum tipo de objeto ou situação. Às qualidades temperamentais esboçam a disposição emocional ampla do indivíduo, por exemplo, seu otimismo, humor, nervosismo ou autoconfiança.

Guilford, define a personalidade criativa como sendo um dos padrões característicos das pessoas criativas e conclui que um padrão criativo é manifestado no comportamento criativo que englobam práticas como inventar, projetar, compor e planejar. Dessa forma, os indivíduos que apresentam esse tipo de comportamento em grau acentuado, são reconhecidas como sendo criativas.

É importante destacar um discurso feito por Guilford em 1950 em um evento da American Psychological Association quando ele argumenta sobre a área da criatividade como um campo ainda pouco explorado e que compreendia apenas $0,2 \%$ de todos os fatores psicológicos de pesquisa. Diante dessa problemática, ele incita o campo para que aumentem esse número em pesquisas e maiores aprofundamentos. Nas décadas seguintes, com base em uma pesquisa da PsycINFO mais de dez mil artigos foram escritos (Kaufman,2009) nas diversas áreas da psicologia como cognitiva, desenvolvimento, clínico, social e industrial, organizacional, além de outros campos como economia, educação e artes. Kaufman diz que a criatividade foi descrita como o mais importante recurso econômico do século XXI.

Em sua maioria, as pesquisas relacionadas a criatividade praticamente se restringem a uma dicotomia em que o " $c$ " minúsculo da criatividade se reserva a criatividade do dia a dia; inclui por exemplo a resolução de problemas diários e capacidade de adaptação às mudanças. Do outro lado, o "C" maiúsculo, faz menção a excelência que ocorre quando o indivíduo resolve um problema ou cria algo que gera um grande impacto sobre a forma como outras pessoas pensam, sentem e vivem suas vidas.

Alencar (2009, p.95) define a criatividade como um fenômeno multifacetado e complexo. Defende que as expressões criativas dependem de fatores que se resumem ao indivíduo como um conjunto de traços de personalidade (iniciativa, persistência, flexibilidade, autoconfiança, independência de pensamento e ação) que ajudam o indivíduo a desfrutar as oportunidades para o desenvolvimento de ideias criativas. Além do indivíduo, os elementos de ordem históricocultural têm papel fundamental nas expressões criativas e possibilidades de desenvolvimento do talento criativo. Alencar também julga os fatores intrapessoais e interpessoais e os fatores individuais e sociais como sendo extremamente significativos na produção criativa do indivíduo e da sociedade.

Para Dimock (1986) criatividade é mais do que originalidade. Trata-se de trazer algo para o mundo que é relativamente novo e possivelmente revolucionário em seu amplo círculo de efeitos.

Gardner (1993) cita um momento importante relativo ao estudo da criatividade e se refere 
a um questionamento feito por Csikszentmihalyi quando substituiu a pergunta "O que é a criatividade?" por "Onde está a criatividade?". Essa troca, de certo modo provocativo por parte de Mihaly, demonstra a complexidade de realizar conceitos relativos ao tema.

Csikszentmihalyi $(2014$, p.47) também diz que esta questão da procura da criatividade não pode ser respondida simplesmente referenciando o indivíduo e seu trabalho. Trata-se de um fenômeno que é o resultado da relação dos três sistemas que, sem um domínio definido culturalmente das ações nas quais a inovação seja possível, o indivíduo não consegue dar início ao processo criativo.

Da mesma forma, sem um grupo de pares para avaliar e validar as adaptabilidades da inovação, torna-se impossível discernir o que é criativo daquilo que é estatisticamente infecundo. Diante desta perspectiva de compreensão, fica explícito que o entendimento de criatividade para ideia ou produto criativo deve ser evidente e de fácil entendimento aos outros indivíduos como também necessitará ser legitimada por especialistas da área e por fim, esta ideia ou produto criativo deverá ser posta no campo cultural a que pertence.

Nesse sentido, complementa Alencar e Fleith (2003, p.63) é de suma importância relevar a influência não somente do ambiente familiar e escolar, mas também dos ambientes social, cultural e o momento histórico, ou seja, para que se entenda de maneira geral em como as novas ideias são produzidas, será preciso levar em consideração tanto as variáveis internas como também as variáveis externas ao indivíduo.

Para que a criatividade seja realmente desenvolvida, (Osborn, 1987, p.51) é categórico ao afirmar que o espírito não somente precisa de exercícios como também adquirir elementos em que o indivíduo possa formar ideias da melhor maneira. Ele coloca a experiência em primeira mão como a mais rica e fértil bagagem que o indivíduo pode receber. A experiência de segunda mão, advinda de recursos como livros, conversas e estímulos visuais também são de certo modo importantes, no entanto, a experiência em primeira mão é viva e absorvida em uma receptividade totalmente individual.

O tema relativo à criatividade, como Mihaly já havia sinalizado, demonstra sua complexidade quando se percebe que apesar de mais de 70 anos de pesquisas nesta área, esse assunto intrigante ainda não se esgota e gera constantemente grandes debates até hoje. Isso porque a criatividade tem sido investigada sob diversas perspectivas teóricas o que prova a sua importância e consequentemente crescimento em pesquisas e publicações científicas.

\section{0 indivíduo criativo}

$\mathrm{Na}$ busca por conceituar a criatividade, existem uma infinidade de concepções teóricas. (Nakano, 2006) cita Puccio e Murdock em sua tese quando estes fizeram uma revisão na área que se referenciava aos conceitos relativos à criatividade em que encontraram mais de 250 (duzentos e cinquenta) publicações na tentativa de caracterizar a criatividade a partir da utilização dos mais diversos tipos de procedimentos, quantitativos e qualitativos.

As aptidões se manifestam de diferentes formas e, portanto, cada indivíduo apresenta um perfil específico em testes de aptidões, ou seja, se uma pessoa tem elevado talento figurativo, certamente ela será mais criativa no campo dos desenhos, pinturas, arte, decoração, etc; no entanto se a capacidade verbal do indivíduo se torna evidente e elevada, provavelmente este será mais criativo no âmbito da escrita. Morais (2011) corrobora com as ideias de Csikszentmihalyi em 
que as aptidões vão além dos esforços e produtos criativos do indivíduo, onde reside a alta criatividade, mas também na manifestação criativa do dia a dia.

É quase que unanimidade concordar que a criatividade tem como principal elemento coadjuvante a motivação. Torna-se estranho e sem sentido criar-se algo sem estar totalmente comprometido e motivado com o que se faz, e mais ainda quando criar, é trazer algo novo, contrário do reproduzir. Nesse caso, o indivíduo se municia tanto por motivações extrínsecas como intrínsecas, este último como sendo de caráter vital.

O indivíduo criativo é aquele que domina conhecimentos, no entanto, para se adquirir conhecimento é preciso ter competência aprofundada acerca do domínio que por sua vez está contida numa teia complexa e repleta de informações de diferentes áreas de erudição, ou seja, para se criar, não basta apenas um conhecimento aprofundado. É preciso ter um amplo conhecimento de caráter multidisciplinar. Morais (2011) valida e reforça os preceitos de Csikzsentimihalyi quanto aos conhecimentos do domínio e considera como fator de extrema relevância a criação do indivíduo no seu dia a dia.

Quanto à personalidade, o indivíduo criativo apresenta algumas características como autonomia, o gosto pelo risco, persistência; embora ter uma personalidade criativa não seja garantia de ser um indivíduo criativo.

Quanto aos processos, mais precisamente aos processos de cognição, estes indivíduos conseguem pensar e processar melhor as informações, são mais flexíveis a perceber visualmente o que os rodeia, utilizam-se mais da imagética, pensam mais facilmente e mais rapidamente na utilização de metáforas ou analogias; além de não somente resolverem problemas como também, descobri-los e cria-los.

O último requisito refere-se ao olhar do outro, como sendo um atributo. Os indivíduos que apresentam esta peculiaridade compõem na maioria das vezes o campo, que consiste na audiência que reconhece a ideia e introduz no domínio. Também pode ser considerado como elemento avaliativo e, por conseguinte, legitimador, o momento sócio histórico de forma a separar o que é e o que não é criativo.

Em meados da década de setenta, os estudiosos da área da psicologia da criatividade estavam preocupados em traçar o perfil do indivíduo criativo e assim expor técnicas que pudessem favorecer a criatividade. Em um outro momento, as atenções se voltaram para a influência de fatores culturais, sociais e históricos no desenvolvimento da criatividade. Nesse contexto, a produção criativa não se resume apenas no indivíduo, mas sim por uma influência de elementos do ambiente onde esse indivíduo está inserido. Guilford (1950), já preconizava que a produtividade criativa se estendia muito além do domínio de inteligência, não se restringindo apenas no indivíduo.

Em relação aos testes de medição da criatividade, Guilford contesta os padrões estereotipados que tentam de alguma forma identificar indivíduos potencialmente criativos por meio de testes de múltipla escolha por exemplo e atenta ao possível erro desse instrumento de medição. Diz que apresentar ao indivíduo criador com seu produto acabado como em um item de múltipla escolha, pode impedi-lo de mostrar o que realmente se quer que ele mostre: A sua criação. Guilford pondera quanto a esses testes de medição da criatividade e sugere que alguns fatores mais cruciais para o desempenho criativo ainda não foram descobertos, e propõe, que 
devemos olhar muito além dos limites do QI se quisermos realmente entender o domínio da criatividade.

O ser humano tem subordinado sua criatividade para muitos aspectos das atividades nos domínios sociais, econômicos e individuais e por isso a investigação no campo da criatividade tem recebido maior atenção principalmente quando se trata de uma abordagem de confluência social. As demais linhas de investigação em criatividade podem ser categorizadas tratando a personalidade, a cognição, o estímulo e a confluência social. Esta última como sendo utilizada de maneira vasta pelos estudiosos da atualidade, sugere que a criatividade pode ser mais bem compreendida pelos meios e contextos sociais.

\section{Conclusão}

Tomando como base o Modelo de Perspectivas de Sistemas de Mihaly Csikszentmihalyi se percebe uma nova possibilidade no que se refere a compreensão sobre o processo criativo em design que se abre, pois, quando recorremos às metodologias clássicas e atuais, o fator "criatividade" se configura como implícito, nesse caso, incorporado apenas a alguma fase metodológica sendo demonstrada na maioria das vezes técnicas de criatividade. Nesse caso, não se considera a possibilidade de experimentar as potencialidades do indivíduo criativo como também em buscar entender que artifícios utilizados pelo campo foram suficientes para legitimar aquela ideia ou produto criativo. Dessa forma, o modelo de perspectivas de sistemas de Mihaly Csikszentmihalyi, atende a essa premissa indo ao encontro do ser criador e dos responsáveis pela audiência, legitimação e incorporação deste produto criativo na cultura.

Com base no Modelo de Mihaly, é possível que o designer (indivíduo criativo), consciente do problema a ser solucionado consiga acessar áreas do Campo e do Domínio de forma a se munir de informações de maior qualidade no que se refere aos propósitos e problemas do de design. Ao acessar o Campo, o designer conseguirá compreender quais critérios de validação os juízes tomam como referência e que normas são tomadas para que as novas ideias produzidas (produtos) sejam legitimadas e incorporadas ao Domínio.

Da mesma forma, a partir do momento em que o designer entende as diretrizes tomadas pelos integrantes do Campo, acredita-se que o processo de design se torna mais estimulante e esclarecedor, pois ele terá maior segurança em acessar e aprofundar elementos de Domínio enriquecendo e incrementando dessa forma seus conhecimentos, oferecendo uma maior amplitude em elementos de erudição com vistas de viabilização e sucesso.

\section{Referências}

ACAYABA, Marlene. Branco e preto: uma história do design brasileiro nos anos 50. São Paulo, 1991. Tese (doutorado) - Faculdade de Arquitetura e Urbanismo da Universidade de São Paulo. [livro]

AFLALO, Marcelo. Os móveis do branco \& preto. São Paulo: Paralaxe, 2005.

ALENCAR, Eunice Soriano de; FLEITH, Denise de Souza, Criatividade: múltiplas perspectivas. Brasília: Ed. UnB, 2009.

AMABILE, Teresa M. What Does a Theory of Creativity Require?, Lawrence Erlbaum Assiciates, Inc. Psycological Inquiry, 1993, Vol.4, No.2, 179-237. 
BAXTER, Mike. Projeto de Produto: Guia prático para design de novos produtos. São Paulo: Edgard Blücher, 1998.

BODEN, Margareth A. Dimensões da criatividade. Porto Alegre: Artmed, 1999.

BONFIM, Gustavo Amarante. Metodologia para desenvolvimento de projetos. João Pessoa: Editora Universitária, 1995.

BORGES, A. Claudia Moreira Salles: Designer. São Paulo: Ed. BEI, 2005.

BORGES, A. Móvel brasileiro contemporâneo. Rio de Janeiro: Aeroplano, FGV Projetos, 2013.

BURDEk, Bernard E. História, teoria e prática do design de produtos / Bernard E.Burdek; trad. Freddy Van Camp. - São Paulo: Edgard Blucher, 2006.

CALS, Soraia. Sérgio Rodrigues. Rio de Janeiro: Icatu, 2000.

CANTI, Tilde. O móvel no Brasil: origens, evolução e características. Edição abreviada por Fernanda Castro Freire. Rio de Janeiro: Cândido Guinle de Paula Machado, 1980.

CARDOSO, Rafael. Design para um mundo complexo. São Paulo: Cosac Naify, 2012.

CLARO, Mauro. Unilabor - desenho industrial e racionalidade moderna. São Paulo,1998. Dissertação (mestrado) - Faculdade de Arquitetura e Urbanismo da Universidade de São Paulo. [livro].

CSIKSZENTMIHALYI, Mihaly. The systems model of creativity: the collected Works of Mihaly Csikszentmihalyi. New York, Springer, 2014.

CSIKSZENTMIHALYI, Mihaly. Does Overinclusiveness Equal Creativity?. Taylor \& Francis, Ltd, Vol. 4, No. 3 (1993), pp. 188-189.

DEBONO, Edward. Lateral Thinking: Creativity Step by Step (New York: Harper and Row, 1970).

DEBONO, Edward. Po: A Device for Successful Thinking (New York: Simon and Schuster, 1972).

DIMOCK, Marshall. Creativity. Public Administration Review. Vol. 46, No. 1 (Jan. - Feb., 1986), pp. 3-7.

ESQUIVIAS, S. M. T. y Muriá, V. I. (2001) "Una evaluación de la creatividad en la Educación Primária." [en línea]. Revista Digital Universitária. 1 de janeiro de 2001, [Consulta: 14 de outubro de 2017].

EVANS, James R. Creativity in MS/OR: Improving Problem Solving through Creative Thinking, Interfaces. Vol. 22, No. 2 (Mar. - Apr., 1992), pp. 87-91.

FERNANDES, Marcela Squires G. Creation: técnica de criatividade para geração de ideias de novos produtos. 2013.124 f. Dissertação (Mestrado em Engenharia de Produção) - Universidade Federal do Rio Grande do Norte, Natal, 2013.

GARDNER, Howard. Mentes que criam: uma anatomia da criatividade observada através das vidas de Freud, Einstein, Picasso, Stravinsky, Eliot, Graham e Gandhi. Porto Alegre, Artes Médicas, 1996.

GUILFORD, J.P. Creativity. University of Southern California, CA, p.444-454, june. 1950.

GORDON, William J. J. Synectics (New York: Harper and Row, 1961); paperback (Toronto: Collier - 
Macmillan, 1968).

GÖTZ, Ignacio L. On Defining Creativity. The Journal of Aesthetics and Art Criticism, Vol. 39, No. 3 (Spring, 1981), pp. 297-301.

HUGERTH, Mina W. Marcenaria Baraúna: móvel como arquitetura. São Paulo: Ed. Olhares, 2017.

KAHL, Cara H.; HANSEN, Hans. Simulating Creativity from a System Perspective:CRESY. Journal of artificial societies ans social simulation, p. 2-27, january. 2015.

KAUFMAN, James C.; STERNBERG, Robert J. Creativity. Taylor \& Francis, Ltd, Vol. 39, No. 4 (Jul. Aug., 2007), pp. 55-58.

KAUFMAN, James C.; BEGUETTO, Ronald A. Beyond big and little: the four C model of creativity. Review of general psychology (march, 2009).

KNELLER, George Frederick, Arte e ciência da criatividade. São Paulo, IBRASA, 1978.

LOBACH, Bernd. Design Industrial: bases para a configuração de produtos industriais. São Paulo: Editora Edgard Blücher LTDA, 2001.

MCINTYRE, Phillip. Paul McCartney and the Creation of 'Yesterday': The Systems Model in Operation. Cambridge University Press, Vol. 25, No. 2, UK, (May, 2006), pp. 201-219.

MCINTYRE, Phillip. Rethinking Creativity Practice in the Light of Mihaly Csikszentmihalyi's Systems Modelo of Creativity. 3rd Global Conference on Creative Engagements - Thinking with Children, Sidney, February. 2007.

MORAES, Dijon de. Análise do design brasileiro: entre mimese e mestiçagem. São Paulo, Edgard Blucher, 2006.

MORAES, Dijon de. Limites do design. São Paulo, Studio Nobel, 1999.

MORAES, Dijon de. Metaprojeto: o design do design. São Paulo: Edgard Blucher, 2010.

MORAIS, Maria de Fátima. Definição e avaliação da criatividade. Braga, FCT, 2001.

NAKANO, Tatiana de Kassia. Teste brasileiro de criatividade infantil: normatização de instrumento no ensino fundamental. 2006. 280f. Tese (Doutorado em Psicologia) PUC - Pontifícia Universidade Católica de Campinas, Campinas, 2006.

OSBORN, Alex F. O poder criador da mente: princípios e processos do pensamento criador e do "Brainstorming". São Paulo, IBRASA, 1987.

OSTROWER, Fayga. Acasos e criação artística. Campinas, Unicamp, 2013.

PARISER, David. Review of "The Nature of Creativity: Contemporary Psychological Perspectives". Robert J.Sternberg, ed., The MIT Press, Vol. 26, No. 2 (1993), pp. 141-144.

PLUMMER, Gordon S. Twenty Highlights in Creativity Research, National Art Education Association. Vol. 35, No. 1 (Jan., 1982), pp. 30-33.

RANGEL JUNIOR, João Francisco Lins Brayner. Criatividade digital: um mundo de ideias e bytes. 2014. 167f. Tese (Doutorado em Psicologia) UFPE - Universidade Federal de Pernambuco, Recife, 2014.

SIMONTON, D. K. Varieties of (Scientific) Creativity: A Hierarchical Model of Domain-Specific 
Disposition,Development, and Achievement. Perspectives on Psychological Science, Vol. 4, No. 5 (September 2009), pp. 441-452

SOLOMON, Miriam. Standpoint and Creativity, Wiley on behalf of Hypatia. Inc., Vol. 24, No. 4 (Fall, 2009), pp. 226-237.

SUMMERS, Irvin; WHITE, Major David E. Creativity Techniques: Toward Improvement of the Decision Process. The Academy of Management Review, Vol. 1, No. 2 (Apr., 1976), pp. 99-107.

TORRANCE, E. Paul. Understanding Creativity: Where to start?. Psychological Inquiry, Vol. 4, No. 3 (1993), pp. 232-234.

WECHSLER, S. M, Criatividade: descobrindo e encorajando. Campinas/SP, Editora Psy, 1993. 